\title{
False Memories for Semantic and Category Associates: Comparing Retrieval Strategies and Retention Interval
}

\author{
Kedarmal Verma ${ }^{a}$, Naveen Kashyap ${ }^{{ }^{b}}$
}

[a] Department of Humanities and Social Sciences, Indian Institute of Technology Guwahati, India

[b] Department of Humanities and Social Sciences, Indian Institute of Technology Guwahati, India

\section{Abstract}

False memories are memories that people believe indeed correspond to actual events from the past. Experimental investigation of false memories involves varied methodologies, including semantic and category associate technique. While the category method depends on the frequency of intra-list items, semantic associate measures semantic association of intra-list items. The present study compares false memory generation through category and semantic associates. Additionally, the mode of retrieval (recall, recognition) and retention interval (short, long) were manipulated to measure their effect on false memory generation. The result of the study suggests that retention interval and mode of retrieval did influence false memories generated using words (semantic associates) and line drawings (category associates).

Keywords: false memory, category associate, semantic associate, recall, recognition

\section{Table of Contents}

Method

Results

Discussion

Conclusion

References 
Psychological Thought, 2020, Vol. 13(2), 322-348, https://doi.org/10.37708/psyct.v13i2.492

Received: 2020-05-07. Accepted: 2020-08-21. Published (VoR): 2020-10-31.

Handling Editor: Natasha Angelova, South-West University "Neofit Rilski", Blagoevgrad, Bulgaria.

${ }^{*}$ Corresponding author at: Department of Humanities and Social Sciences, Indian Institute of Technology Guwahati, India. E-mail: naveen.kashyap@iitg.ac.in

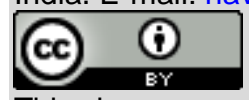

This is an open access article distributed under the terms of the Creative Common Attribution License (https://creativecommons.org/licenses/by/4.0), which permits unrestricted use, distribution, and reproduction in any medium, provided the original work is properly cited.

Memories are central to cognition as they connect people not only to their past but also help them in planning for the future. Memories, however, are not free of errors as the very processes of memory formation are rigged by numerous factors that can contaminate and distort the true nature of memory. Human memories are malleable as they are susceptible to suggestions from others which lead to remembering of events that genuinely never happened in reality. Investigation on memory errors started at the beginning of the present century through the works of Alfred Binet (1857-1911) on suggestive questioning, Jean Piaget (1896-1980) on constructive texts and Frederic Bartlett (1886-1969) narrative texts. They proposed the reconstructive nature of human memory which forms the basis of present-day false memory research. In recent two decades, research on false memory (Pezdek \& Lam, 2007) experiment with variables like presentation modality (Hunt \& McDaniel, 1993; Johnson, Nolde \& De Leonardis, 1996; Percer \& Roediger, 2001; Smith \& Hunt, 1998), methodological differences (Israel \& Schacter, 1997; Schacter et al., 2001), retention intervals and deep level of processing (Barclay \& Wellman, 1986; Liecht, 1968; Reyna \& Kiernan, 1994; Sachs, 1967; Thapar \& McDermott, 2001), stimulus presentation manner (Mather et al., 1997; McDermott, 1996; Toglia et al., 1999), presentation duration of list words (McDermott \& Watson, 2001; Sommers \& Lewis, 1999; Toglia \& Neuschatz, 1996).

Several methodologies for inducing false memories in humans are proposed by recent false memory literature. The aim of the present study is to compare the semantic associate and category associate methods of producing false memory. Two efficient methodologies namely semantic associates and category associates were employed to induce false memories in the present study. The semantic associate uses words for inducing false memory, the category associate uses simple line drawings for inducing false memories. The DRM paradigm (Roediger

Psychological Thought

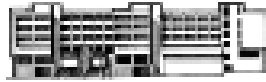

2020, Vol. 13(2), 322-348

South-West University "Neofit Rilski"

https://doi.org/10.37708/psyct.v13i2.492 
\& McDermott, 1995) involves presenting semantically related word and retrieving them on a memory test at a later time. Words demonstrating highest semantic relations with list words (critical lures) are selectively removed from the lists. Studies reported that volunteers at retrieval falsely reproduce critical lure word with high frequency despite the words being never shown to the subjects. Deese-Rodreiger-McDermott (DRM) paradigm depends on associative strength between semantically related words. Research evidence reported that stronger associative strengths between list words led to higher recall of list words (true targets) and low intrusion recall (Deese, 1959a).

Similarly, a strong association between list words and critical words produced false recall of critical words (Deese, 1959b). Additionally, research reported a negative correlation between length of critical words and false recall (Roediger et al., 2001). Similarly, raw frequency (Kucera \& Francis, 1967), concreteness (Nelson et al., 2004; Paivio et al., 1968; Toglia \& Batting, 1978), forward associative strength (Nelson et al., 2004) and backward associative strength (Nelson et al., 2004) are other variables that modulate false memory production on DRM. Alongside the semantic associate methodology, another competing method for induction of false memory is the category associate method. The paradigm for category associate involves randomly presenting few exemplars per category to subjects and at the time of retrieval, making volunteers distinguish studied exemplar and related non-studied exemplars (Hintzman, 1988). For example, reading material is a category for booklet, pamphlet, comic book, broacher (possible exemplars). Brainerd et al. (1995) investigated false memory formation in children for category associates and reported that younger children were more prone to false memories and this effect was enhanced across longer retention durations (Brainerd \& Reyna, 1996). The use of black and white (Strack \& Bless, 1994) or colored (Koutstaal \& Schacter, 1997) pictures produced consistent results.

The methodologies stated above employ different stimuli for inducing false memories. Whereas semantic associates use words as stimuli, the category associates use pictures as stimuli. The processing of words and images have different mechanisms. Research suggested that both pictures (pictorial stimuli) and words (language stimuli) are processed differently in the brain. Thus it would be interesting to compare false memories induced using words and pictures. It would give insight into the mechanisms of false memory formation in humans. 
False memory tasks used in the present study use either words or images as stimuli which form different mental representations. The retrieval of these mental representations during task performance may get biased due to nature of retrieval strategy. The effects of retrieval strategy (recall, recognition) on the false memories induced using semantic and category associates was also tested in the present study.

\section{Method}

\section{Participants}

Twenty-four healthy participants with average age $M=19.27 S D=1.27$ years, all males, volunteered for the memory experiment. The study utilized mixed model design where subjects were assigned to either the recall or recognition group. Participants within a group performed both the semantic and category associate task. Volunteers were undergraduate students of Indian Institute of Technology Guwahati, India who were compensated with partial course credit for the participation. All participants were free from a severe medical and psychiatric condition with average memory.

\section{Material}

Category associate task: Simple line drawings of examplers induced false memories. Subjects learned ten category lists with ten line drawing of examplers of a category on each list. The line drawing pictures used in each category list were categorically associated and were extracted from previously developed picture database (Battig \& Montague, 1969). Line drawing pictures were presented using e-prime on the centre of the computer screen in sequential order. Line drawing pictures in each list were arranged in descending order of their frequency of availability (Seamon et al., 2000).

Semantic associate task: DRM paradigm was used to induce false memory from pre-selected word lists. Subjects studied ten semantically associated lists with ten words in each list. The words used were semantic associates and were extracted from previously developed false memory word corpus (Deese, 1959a, 1959b; Roediger \& McDermott, 1995; Roediger et al., 2001; Stadler et al., 1999). Words were presented using e-prime on the centre of the computer 
screen with each word written in size 14 Time New Roman font. Words on each list were arranged in descending order of their backward association strength (BAS) value (McEvoy et al.,1999). Within lists factors, i.e. word length and backward association strength value was made constant across all lists to maintain consistency.

\section{Procedure}

Subjects in each group (recall, recognition) were made to study the given lists of stimuli (words in DRM method, and line drawings in CA method) and later perform on the retrieval tests assigned for that group. At the beginning of the experiment, each participant filled behavioral questionnaires that included Mood questionnaire, MMSE, Memory and Attention test, Memory Functioning Questionnaire.

\section{Encoding}

In category associate (CA) method, a total of ten category lists with ten exemplar pictures (related to category) in each category list were presented. The subjects were instructed to attend and commit to memory displayed images for a later retrieval test. The lists were presented at the rate of 3 seconds per picture with an inter-stimulus interval of 2 seconds and an inter list interval of 5 seconds. List words were sequentially presented during the study phase, but at the time of the test phase, intra-list words were randomly presented. The experiment was designed in E-Prime Software Version 2.0.

In semantic associate (SA) method, a total of ten lists with ten words in each list were presented. The subjects were instructed to attend and commit to memory displayed words for a later retrieval test. The lists were presented at the rate of 3 seconds per word with an interstimulus interval of 2 seconds and an inter list interval of 5 seconds. List words were sequentially presented during the study phase as well as during the test phase. The experiment was designed in E-Prime Software Version 2.0.

\section{Retrieval}

At recognition, participants provided the old/new judgment for each presented stimuli. Responses generation on the recognition test was self-paced by participants. Each recognition list contained three old stimuli (pictures in category associate/words in semantic associate) from 
encoding, three new stimuli (pictures in category associate/words in semantic associate) which were not presented at encoding (distractor), and one critical lure (image having highest familiarity value, the word having highest semantic relation value). Word repetition on lists was prevented by introducing a distraction task following list learning. The whole experiment runs for approximately 40 minutes in both the methodologies.

At recall, participants were free to recall the list words learned at encoding for semantic and category associates. In the recall of category associates, participants have to reproduce the name of the line-drawings from the encoding list, and in semantic associates, participants reproduced words from encoding list. All the responses were taken on plain white paper. No time limit was set for recall of list words. Distractor task following encoding prevented repetition of list words.

\section{Memory Measurement}

In the free recall, three categories are made viz. true target words (studied words during encoding), critical lures (item with the highest semantic or categorical association with encoding list words: false memory identifier), and intrusions (words similar to list words). In recognition, first, the raw memory measure was calculated and then using non-parametric signal detection measurements, the sensitivity, and the response bias were calculated for final analysis (PardillaDelgado \& Payne, 2017). During raw memory measures, the true targets rates were defined as the hit rate [h]. It is calculated by dividing the number of words that were previously learned and identified as "old" by the total number of presented study words. The false rate is defined as false alarm rate to critical lures [fc]. It is calculated by dividing the number of related lures identified as "old" by the total number of related lure words. The foil rate is defined as false alarm rate to foils [fr]. It is calculated by dividing the "old" response given to unrelated foils by a total number of unrelated foils.

Non-parametric measure of the signal detection theory was used to calculate sensitivity (a') for true [hit rate and foil rate] and false recognition [false rate and foil rate]. Response bias (b") were also obtained for both true and false recognitions (Donaldson, 1992; Snodgrass \& Corwin, 1988). 


\section{Calculating sensitivity (a')}

True recognition

If $(h>f r) ;=1 / 2+[(h-f r)(1+h-f r] /[4 h(1-f r)]$

Else if, $(f r>h) ;=1 / 2+[f r-h)(1+f r-h)] /[4 \times f r(1-h)]$

False recognition:

If $(f c>f r) ;=1 / 2+[(f c-f r)(1+f c-f r)] /[4 \times f c(1-f r)]$

Else if, $(f r>f c) ;^{\prime}=1 / 2+[(f r-f c)(1+f r-f c)] /[4 \times f r(1-f c)]$

\section{Calculating bias ( $\left.b^{\prime}\right)$}

True targets

If $(h>f r) ;=[h(1-h)-f r(1-f r)] /[h(1-h)+f r(1-f r)]$

Else if, $(f r>h)=[f r(1-f r)-h(1-h)] /[f r(1-f r)+h(1-h)]$

False words

If $(f c>f r)=[f c(1-f c)-(f r(1-f r)] /[f c(1-f c)+f r(1-f r)]$

Else if, (fr $>$ false alarm rate $)=[f r(1-f r)-f c(1-f c)] /[f r(1-f r+f c(1-f c)]$

Sensitivity varies between the range from 0.00 to 1.00 , where the higher score of sensitivity indicates the greater sensitivity and low score shows lower sensitivity. The response bias varies from -1.00 to +1.00 , where the negative value of response bias indicates the liberal bias, a positive value of response bias shows the conservative bias. If the value of response bias is equal to zero, then it means the neutral bias.

\section{Data analysis}

The results are presented as mean correct responses of studied stimuli (pictures and words), intrusions (pictures and words), and critical lures (picture and words) for recall test. For the recognition test, sensitivity and response bias was measured to analyze the scores of critical lures and true target words. Mixed factorial within-subject repeated measure analysis of variance (ANOVA) was used to measure the effectiveness of false memory methodologies for both the recall and recognition retrieval strategy across short and long retention interval. Bonferroni post hoc analysis was used to examine the interaction effects. 


\section{Results}

1) For Recall Test: Mixed factorial within-subject repeated measure ANOVA: 2 [Task Type: (SA, CA)] x 3 [Retention intervals: (Immediate, one day, and two days)] was conducted on the data obtained from the experiment. The following measures were analyzed:

Critical Lures: The main effect of task type for critical lures was found to be non-significant $\left.F(1,11)=0.514, p>.05, \eta^{2}=.049\right)$ suggesting that on both semantic and category associates tasks the subjects were retrieving equal critical lures. Similarly, no significant role of retention interval between learning and retest was reported on critical lure retrievals for semantic and category task $F(2,20)=0.262, p>.05, \eta^{2}=.026$. No significant interaction was reported $F(2,20)=0.224, p>.05$. (See Table 01)

Intrusions: The main effect of task type for intrusion was not significant $F(1,10)=2.168, p>$ $.05, \eta^{2}=.178$ suggesting that an equal number of new words (not present in the learning lists) were recalled by the participants on semantic and category associate task. Similarly, no significant role of retention interval between learning and recall was reported $F(2,20)=$ 1.297, $p>.05, \eta^{2}=.115$. No significant interaction was reported $F(2,20)=2.890, p>.05$. (See Table 01)

True Targets: The main effect of task type for true targets were significant $F(1,10)=$ $31.759, p<.05, \eta^{2}=.761$ suggesting that participants recall a significantly different number of true targets (list words from learning) on the semantic and category task. Similarly, it was found that recall of list words for the semantic and category task varied significantly across the three retrieval intervals spanning between learning and recall $F(2,20)=17.125, p<.05$, $\eta^{2}=.633$. No significant interaction was reported $F(2,20)=1.481, p>.05$. (See Table 1 )

2) For Recognition Test: Mixed factorial within-subject repeated measure ANOVA: 2 [Task Type: (SA, CA)] x 3 [Retention intervals: (Immediate, one day, and two days)] was used to analyze recognition scores for category and semantic tasks. Recognition scores in terms of 
sensitivity and response bias were analyzed separately for three different measures of false memory.

Critical Lure: The main effect of task type was found to be non-significant for critical lures in recognition test $F(1,12)=0.009, p>0.05, \eta^{2}=.001$ however, a significant effect of retention interval was reported $F(2,24)=4.703, p<0.05, \eta^{2}=.282$. The results suggested that the number of critical lures recognized by participants did not differ across the semantic and category task. Still, critical lures identification significantly varied across the varied retention intervals. Also, a significant task $x$ retention interval was reported. Bonferroni posthoc analysis reveals that for the semantic task, the critical lure score significantly differed between immediate and 24-hour testing, but this was not true for any other condition. (See Table 2)

The response bias for critical lured on semantic task is conservative on immediate retrieval, and shifts to liberal bias on delayed retrievals. In category task, the response bias remained conservation for all retention intervals (See Table 2). The main effect of task type $F(1,12)=$ $10.495, \mathrm{p}<.05, \eta^{2}=.467$ and retention interval $F(2,24)=9.544, p<.05, \eta^{2}=.443$ in response bias was found to be significant.

True Targets: The main effect of task type for true targets are found to be significant $F$ (1, $12)=46.194, p<.05, \eta^{2}=.794$. Also main effect of retention intervals $F(2,24)=20.565, p<$ $0.05, \eta^{2}=.632$ on true target recognition was also significant. The above results suggested that participants differed on the number of true targets (list words from learning) recognition for the semantic and category task. Also, the recognition of true targets varied when the recognition test was conducted after different retention intervals. Mean values of sensitivity are reported in Table 2.

The response bias of true target pictures in category and semantic task, was conservation on immediate recognition test but this bias shifted to liberal on delayed testings (see table 02). The main effect of task type $F(1,12)=0.312, p>.05, \eta^{2}=.025$ found to be nonsignificant. The main effect of retention interval found to be significant $F(2,24)=10.377, p<$ $.05, \eta^{2}=.464$. 
Table 1.

Memory Performance Descriptive Statistics in Recall Test Across Task Type

\begin{tabular}{cccccccc}
\hline \multirow{2}{*}{$\begin{array}{c}\text { Dependent } \\
\text { Measure }\end{array}$} & \multicolumn{5}{c}{ DRM Task (for Words) } & \multicolumn{3}{c}{ CA Task (for Pictures) } \\
& Immediate & 24 Hours & 48 Hours & Immediate & 24 Hours & 48 Hours \\
\hline Critical Lures & $2.09 \pm 1.57$ & $2.27 \pm 1.27$ & $2.36 \pm 1.12$ & $2.63 \pm 1.43$ & $2.45 \pm 1.43$ & $2.63 \pm 1.56$ \\
Intrusions & $2.81 \pm 2.40$ & $2.90 \pm 2.38$ & $4.54 \pm 2.76$ & $5.63 \pm 4.58$ & $4.45 \pm 3.85$ & $5.00 \pm 4.71$ \\
True Targets & $25.18 \pm 6.17$ & $19.45 \pm 4.41$ & $20.09 \pm 4.70$ & $38.09 \pm 9.62$ & $32.00 \pm 9.03$ & $29.54 \pm 9.85$ \\
\hline
\end{tabular}

Table 2 .

Sensitivity (A') and Response Bias (B") of Critical Lures and True Target Words Across Task Type

\begin{tabular}{ccccccc}
\hline \multirow{2}{*}{$\begin{array}{c}\text { Dependent } \\
\text { Measure }\end{array}$} & \multicolumn{5}{c}{ DRM Task (for Words) } & \multicolumn{3}{c}{ CA Task (for Pictures) } \\
\hline A' & Immediate & 24 Hours & 48 Hours & Immediate & 24 Hours & 48 Hours \\
\hline Critical Lures & $.80 \pm .07$ & $.68 \pm .13$ & $.66 \pm .13$ & $.71 \pm .11$ & $.72 \pm .09$ & $.72 \pm .11$ \\
True Targets & $.83 \pm .07$ & $.74 \pm .09$ & $.71 \pm .10$ & $.95 \pm .09$ & $.92 \pm .05$ & $.91 \pm .06$ \\
\hline B" & & & & & & \\
\hline Critical Lures & $0.10 \pm 0.45$ & $-0.11 \pm 0.30$ & $-0.12 \pm 0.29$ & $0.50 \pm 0.39$ & $0.31 \pm 0.27$ & $0.26 \pm 0.35$ \\
True Targets & $0.11 \pm 0.39$ & $-.011 \pm 0.06$ & $-0.14 \pm 0.10$ & $0.18 \pm 0.71$ & $-0.30 \pm 0.47$ & $-0.29 \pm 0.69$ \\
\hline
\end{tabular}


Figure 01

Mean scores of recall memory (A) Overall mean scores of CL, Intrusion and Studied words across DRM and CA tasks, (B) Mean scores of CLs across retention intervals between DRM and CA task, (C) Mean scores of intrusions across retention intervals between DRM and CA task, and (D) Mean scores of studied words across retention intervals between DRM and CA task. $(p<0.05)$
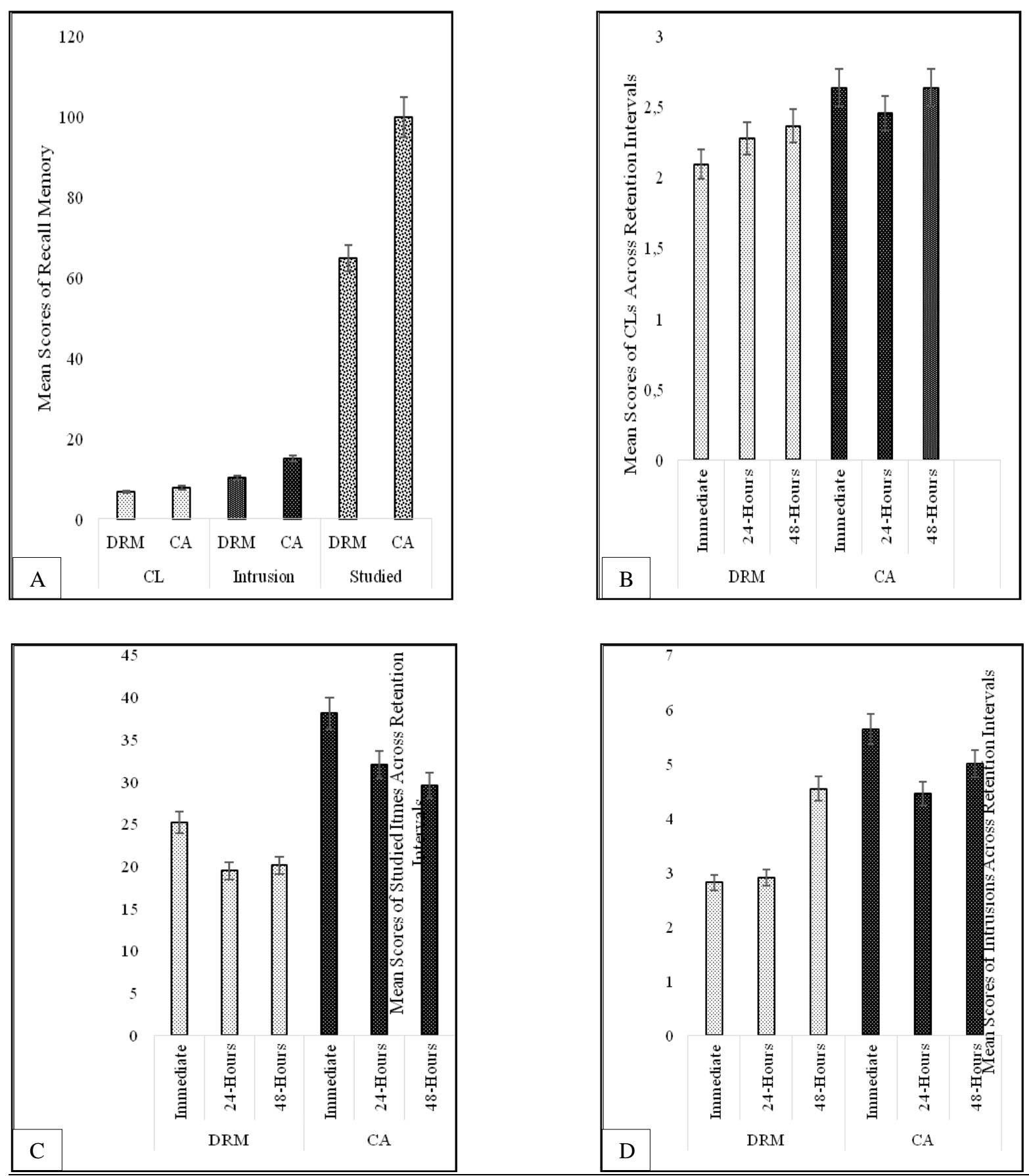

Psychological Thought South-West University "Neofit Rilski" 2020, Vol. 13(2), 322-348

https://doi.org/10.37708/psyct.v13i2.492 
Figure 02

Mean scores of CLs recognition, (A) Sensitivity of CLs across DRM and CA task, (B) Sensitivity of CLs across retention intervals between DRM and CA Task, (C) Response bias of CLs across DRM and CA task, and (D) Response bias of CLs across all retention intervals between DRM and CA task.
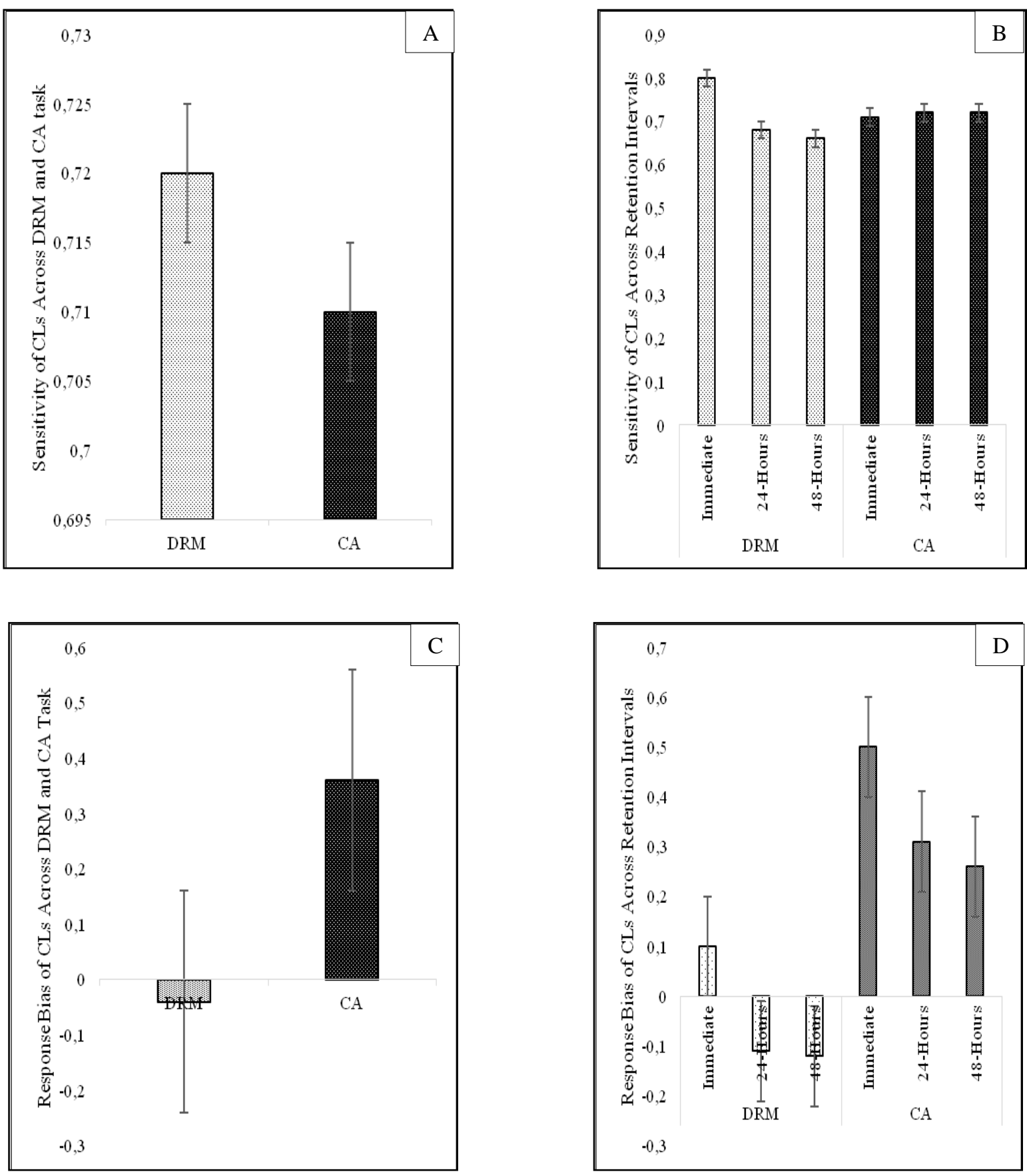

Psychological Thought

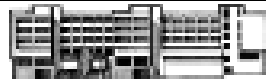
2020, Vol. 13(2), 322-348

South-West University "Neofit Rilski" https://doi.org/10.37708/psyct.v13i2.492 
Figure 03

Mean scores of studied words recognition, (A) Sensitivity of studied words across DRM and CA task, (B) Sensitivity of studied words across retention intervals between DRM and CA Task, (C) Response bias of studied words across DRM and CA task, and (D) Response bias of studied words across all retention intervals between DRM and CA task.
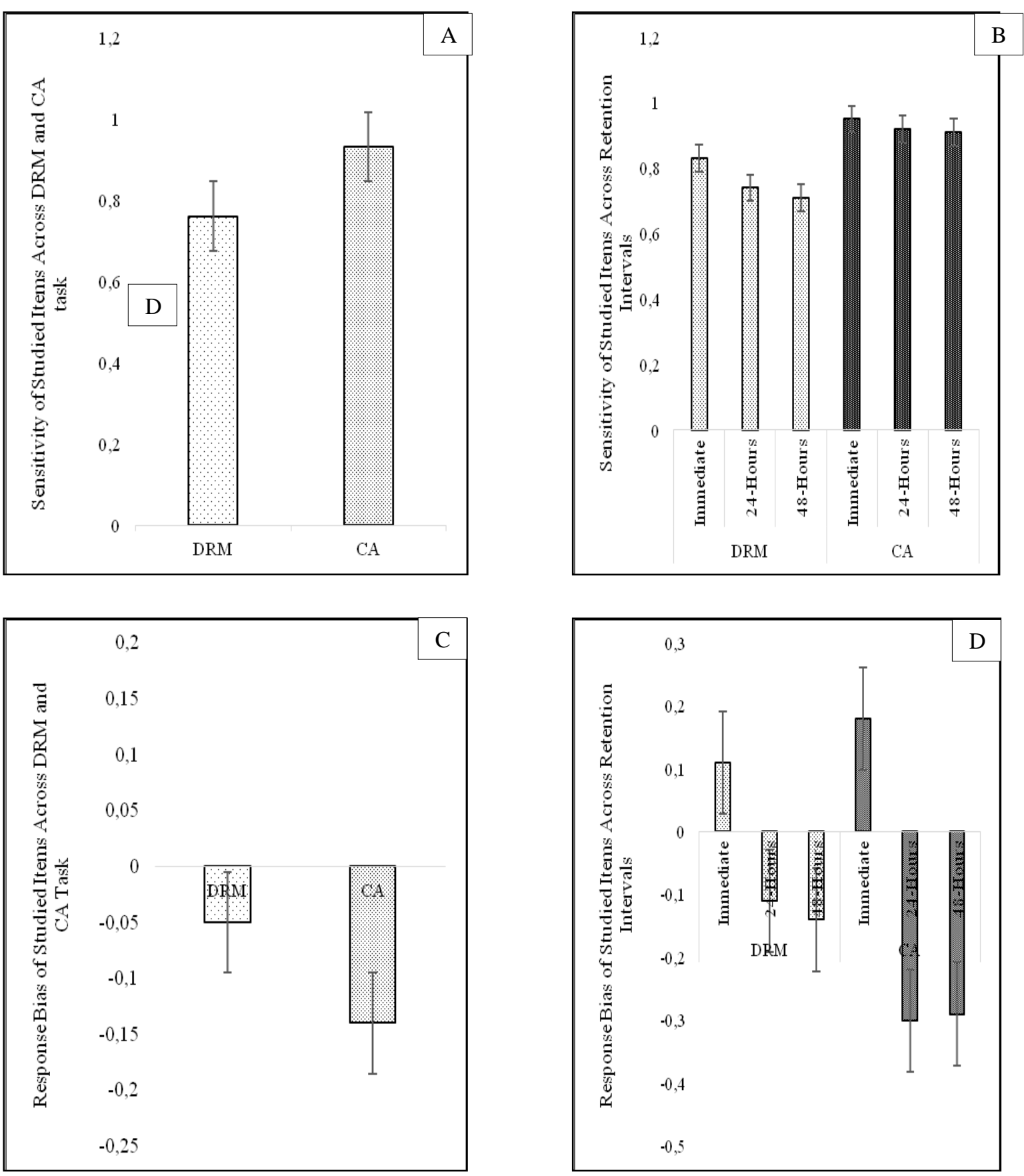


\section{Discussion}

In the present study, it was observed that both the semantic and category associate are equally effective in the production of false memory (critical lures) across both recalls and recognition retrieval strategies. Additionally, it was reported that true target words were better remembered for category associates over semantic associates suggesting that line-drawings (pictures) were recognized more than words. These would mean that old pictures are retrieved with greater accuracy over old words suggesting the role of picture superiority effect.

Retrieval using recall test report that semantic and category associate generate an equal amount of critical lures and intrusions (false memory identifier) in the present study. One possible reason for this could be that the mental representation for images (in terms of their meaning) and words (in terms of their labels) are somewhat identical (Nelson et al., 1976). Additionally, it was observed in previous studies that false memory recall is influenced by semantic processing (Toglia et al., 1999) via visual presentation and the results showed that there were no differences between pictures and words for false recall. It was reported in a study that aural formats induced high false recall than words or pictures (Beauchamp, 2002). In the same study, a lower rate of false recall for pictorial stimuli than words was reported, but these differences were not significant. In the present study, the recall of true target pictures was higher than words which reflect that the images have more physical characteristics, like vividness and meaning (Bousfield et al., 1957) than words which make them easily memorable. The picture superiority effect (Pavio, 1971; Weldon \& Roediger, 1987) suggest that pictures contain more sensory-perceptual details than words (rich in phonetic and orthographic information). The above fact could have lead to increased true target recall of category associates (pictures) over semantic associates (words).

In the present study, retrievals using recognition report similar rates of false recognition for the category and semantic associates but different rates of recognition of true targets. The true target identification was more in category (picture stimuli) than semantic (word stimuli) associates. Picture stimuli are more vivid and rich in sensory-perceptual content (Pavio, 1971; Weldon \& Roediger, 1987) and have direct access for their semantic processing. Word stimuli are rich in their phonetic, orthographic codes and have lexical access only (Convay \& 
Gathercole, 1990; Nelson et al., 1977). These factors could be attributed to results obtained from differences in recognition rates for the category and semantic associates. Previous research suggests that false recognition and true recognition both rely more on semantically associated memory than the memory of distinctive perceptual details and that false recognition has less access to perceptual information than true recognition (Mather et al., 1997; Norman \& Schacter, 1997). The present study findings are contrary to previous researches which show that words lead to higher false recognition than pictures. The present study reports insignificant differences between semantic and category associate induced false memory suggesting that both methods are equally effective in producing false memory. These non-significant differences can be attributed to differences in the task processing by the semantic and category associates. In the semantic associate task, list words are semantically associated (Roediger \& McDermott, 1995) with each other and critical lure. In the category associate task, exemplars on the list are categorically associated, and the exemplar with highest associative strength becomes the critical lure (Hintzman, 1988). This present study employs a within-subject design, whereas previous researches have used a between-subject design with semantic associates (Israel \& Schacter, 1997) and category associates (Seamon et al., 2000). Israel \& Schacter (1997) found that critical lures words are more remembered than pictorial lures. They argued that pictures are more informative and distinctive than words.

For words, only available perceptual information is present for identification whereas, in images, additional perceptual details are present which helps in remembering more words (Benmergui et al., 2017; Schacter, et al., 1999). In the present study, across the retention intervals, it was found that sensitivity of studied (true target) words decreased from immediate to 48-hours of delay for both semantic and category associate task. In contrast, the sensitivity of critical lures in semantic associate decreased from immediate to 48-hours of delay while for category associate, no change was observed across immediate and delayed retention interval. The studied item's results for category associates are similar to Seamon et al. (2000). The response bias in the present study remains conservative across all retrieval intervals for category associate task, which is also similar to Seamon et al. (2000). In semantic associate task, the response bias is conservative during immediate retrieval but tend to become more liberal on delayed retrievals. The results of the present study are not directly comparable to previous studies done on the same theme. The present study has several procedural differences in terms 
of stimuli used (line drawings and words), stimuli presentation (list length, list type), retention interval (immediate, short delay and long delay) with other similar studies.

The underlying process and underlying representation of converging associates (for words) and category associates (for pictures) can be explained by implicit activation hypothesis (Underwood, 1965) and fuzzy trace theory (Brainerd \& Reyna, 1998). According to Implicit activation hypothesis, participants will activate the representations of related non-presented exemplars of category which they have studied during the encoding phase. High-frequency critical lure exemplars will be activated more than low-frequency critical lures when the associative strength of studied exemplars is strong in the category list. Still, this hypothesis cannot explain all the assumptions of false memory induction. For example, it is not applicable for the explanation of the differential effect of retention intervals for correct and false recognitions. It is observed that over 24 hours of retention interval, the true target hits decreases and critical lure identification increases (Payne et al., 1996). Our finding also reports that true targets retrieval accuracy decreases across long delays, whereas critical lures identifications increase over small delays but show a decline across longer delays. The differential effect of retention intervals can be interpreted with the understanding of fuzzy trace theory. It explains that the memory traces are presented in two forms (Brainerd et al., 1995a, b; Reyna \& Brainerd, 1995), viz. the verbatim trace which stores the surface details of the stimuli and gist trace which store the theme or gist of stimuli. True recognition is associated with verbatim traces, and false recognitions of stimuli are primarily associated with gist trace. In semantic associates (words) and category associates (pictures), false recognitions of related non-presented stimuli are encountered due to the gist representations. In converging associates, the theme words of the list words impart the gist representation (e.g. sleep for the list of the night, pillow, dark, dream, etc.). In contrast, in category associates, the theme of the list words imparts the abstract category name as the gist representation (e.g. professions for lawyer, electrician, plumber, etc.). The concrete name for gist representation of profession category would be a doctor as it represents the prototypical features or the category profession which is the high-frequency critical lure.

This present study has found the converging associate (DRM task) and category associates (CA task) both are equally effective in induction of false memory. This study is crucial as it found 
the effectiveness of false memory induction methods across words and pictures across three retention intervals. It was found that semantic associates and category associates both can induce false memory, and both can be explained with the implicit activation of critical lures and gist representation of critical lures explained by fuzzy trace theory.

\section{Conclusion}

The present study investigated false memory formation on semantic and category associates over short and extended retention intervals. Retrievals were obtained using both recall and recognition. It could be concluded that on recall both semantic and category associates generated nearly similar false memories. Semantic associates on recognition generated lower false memories but only on short retrieval interval. The difference in false memory generation could be a direct effect of the retrieval process employed by recall and recognition.

\section{Limitations}

The present study has some limitations which can be addressed in future studies. The determination of list length might be the most significant factor in determining false memories. Although average length list (10 items) was used, future studies can dwell on the right balance on list length and associate strength between list members. Another limitation is the use of both recall and recognition testing on each volunteer. Future studies can use separate volunteer groups for recall and recognition testing. Future, studies can also experiment with the order of recall and recognition on the same volunteers and enlist difference, if any, on false memories.

\section{Funding/Financial Support}

The authors have no funding to report

\section{Other Support/Acknowledgement}

The authors have no support to report.

\section{Competing Interests}

The authors have declared that no competing interests exist. 


\section{References}

Barclay, C., \& Wellman, M. (1986). Accuracies and inaccuracies in autobiographical memories. Journal of Memory and Language, 25(1), 93-103. https://doi.org/10.1016/0749-596X(86)90023-9

Battig, W., \& Montague, W. (1969). Category norms of verbal items in 56 categories A replication and extension of the Connecticut category norms. Journal of Experimental Psychology, 80 (3), 1-46. https://philpapers.org/go.pl?id=BATCNO\&proxyld=\&u=http\%3A\%2F\%2Fdx.doi.org\%2F10.1037\% 2Fh0027577

Beauchamp, H. M. (2002). Aural, visual, and pictorial stimulus formats in false recall. Psychological reports, 91(3), 941-951. https://doi.org/10.2466/pr0.2002.91.3.941

Benmergui, S. R., McKelvie, S. J., \& Standing, L. G. (2017). Beneficial Effect of Pictures on False Memory in the DRMRS Procedure. Current Psychology, 36(1), 136-146. https://psycnet.apa.org/doi/10.1007/s12144-015-9394-y

Bousfield, W. A., Esterson, J., \& Whitmarsh, G. A. (1957). The effects of concomitant colored and uncolored pictorial representations on the learning of stimulus words. Journal of Applied Psychology, 41(3), 165-168. https://psycnet.apa.org/doi/10.1037/h0047473

Brainerd, C. J., Reyna, V. F., \& Brandse, E. (1995a). Are children's false memories more persistent than their true memories? Psychological Science, 6(6), 359-364. https://doi.org/10.1111\%2Fj.14679280.1995.tb00526.x

Brainerd, C., Reyna, V., \& Kneer, R. (1995b). False-recognition reversal: When similarity is distinctive. Journal of Memory and Language, 34(2), 157-185. https://psycnet.apa.org/doi/10.1006/jmla.1995.1008

Brainerd, C., \& Reyna, V. (1996). Mere memory testing creates false memories in children. Developmental Psychology, 32(3), 467-478. https://psycnet.apa.org/doi/10.1037/00121649.32.3.467

Brainerd, C. J., \& Reyna, V. F. (1998). When things that were never experienced are easier to "remember" than things that were. Psychological Science, 9(6), 484-489. https://doi.org/10.1111\%2F1467-9280.00089 
Conway, M. A., \& Gathercole, S. E. (1990). The effects of writing upon memory: Evidence for a translational hypothesis. Quarterly Journal of Experimental Psychology, 42A, 513-527. https://doi.org/10.1080\%2F14640749008401235

Deese, J. (1959a). Influence of inter-item associative strength upon immediate free recall. Psychological Reports, 5(3), 305-312. https://doi.org/10.2466\%2Fpr0.1959.5.3.305

Deese, J. (1959b). On the prediction of occurrence of particular verbal intrusions in immediate recall. Journal of experimental psychology, 58(1), 17-22. https://doi.apa.org/doi/10.1037/h0046671

Donaldson, W. (1992). Measuring recognition memory. Journal of Experimental Psychology: General, 121(3), 275. https://psycnet.apa.org/doi/10.1037/0096-3445.121.3.275

Grady, C., McIntosh, A. R., Rajah, M. N., \& Craik, F. I. (1998). Neural correlates of the episodic encoding of pictures and words. Proceedings of the National Academy of Sciences, 95(5), 2703-2708. https://dx.doi.org/10.1073\%2Fpnas.95.5.2703

Hintzman, D. (1988). Judgments of frequency and recognition memory in a multiple-trace memory model. Psychological review, 95(4), 528-551.

Hunt, R., \& McDaniel, M. (1993). The enigma of organization and distinctiveness. Journal of Memory and Language, 32(4), 421-445. https://doi.org/10.1006/jmla.1993.1023

Israel, L., \& Schacter, D. (1997). Pictorial encoding reduces false recognition of semantic associates. Psychonomic Bulletin \& Review, 4(4), 577-581. https://doi.org/10.3758/BF03214352

Johnson, M., Nolde, S., \& De Leonardis, D. (1996). Emotional focus and source monitoring. Journal of Memory and Language, 35(2), 135-156.

Koutstaal, W., \& Schacter, D. (1997). Gist-based false recognition of pictures in older and younger adults. Journal of Memory and Language, 37(4), 555-583. https://doi.org/10.1006/jmla.1997.2529

Kucera, H., \& Francis, W. (1967). Computational analysis of present-day American English. Brown University Press.

Leicht, K. (1968). Recall and judged frequency of implicitly occurring words. Journal of Verbal Learning and Verbal Behavior, 7(5), 918-923. https://doi.org/10.1016/S0022-5371(71)80022-1

Mather, M., Henkel, L., \& Johnson, M. (1997). Evaluating characteristics of false memories: 
Remember/know judgments and memory characteristics questionnaire compared. Memory \& Cognition, 25(6), 826-837.

McDermott, K. (1996). The persistence of false memories in list recall. Journal of Memory and Language, $35(2), 212-230$.

McDermott, K., \& Watson, J. (2001). The rise and fall of false recall: The impact of presentation duration. Journal of Memory and Language, 45(1), 160-176. https://doi.org/10.1006/jmla.2000.2771

McEvoy, C., Nelson, D., \& Komatsu, T. (1999). What is the connection between true and false memories? The differential roles of interitem associations in recall and recognition. Journal of Experimental Psychology: Learning, Memory, and Cognition, 25(5), 1177-1194. https://doi.org/10.3758/BF03196177

Nelson, D. L., Reed, V. S., \& Walling, J. R. (1976). Pictorial superiority effect. Journal of Experimental Psychology: Human Learning and Memory, 2(5), 523-528. https://psycnet.apa.org/doi/10.1037/0278-7393.2.5.523

Nelson, D. L., Reed, V. S., \& McEvoy, C. L. (1977). Learning to order pictures and words: A model of sensory and semantic encoding. Journal of Experimental Psychology: human learning and memory, 3(5), 485-497. https://psycnet.apa.org/doi/10.1037/0278-7393.3.5.485

Nelson, D., McEvoy, C., \& Schreiber, T. (2004). The University of South Florida free association, rhyme, and word fragment norms. Behavior Research Methods, Instruments, \& Computers, 36(3), 402407.

Norman, K. A., \& Schacter, D. L. (1997). False recognition in younger and older adults: Exploring the characteristics of illusory memories. Memory \& Cognition, 25(6), 838-848. https://psycnet.apa.org/doi/10.3758/BF03211328

Nyberg, L., Mclntosh, A., Houle, S., Nilsson, L., \& Tulving, E. (1996). Activation of medial temporal $\begin{array}{llll}\text { structures during episodic memory retrieval. Nature, 380(6576), } & \text { 715-717. }\end{array}$ https://psycnet.apa.org/doi/10.1038/380715a0

Pardilla-Delgado, E., \& Payne, J. D. (2017). The impact of sleep on true and false memory across long delays. Neurobiology of learning and memory, 137, 123-133. https://doi.org/10.1016/j.nlm.2016.11.016 
Paivio, A., Yuille, J., \& Madigan, S. (1968). Concreteness, imagery, and meaningfulness values for 925 nouns. Journal of Experimental Psychology, 76(1), 1-25. https://doi.org/10.1037/h0025327

Paivio, A. (1971). Imagery and verbal processes. Holt, Rinehart, \& Winston.

Perani, D., Schnur, T., Tettamanti, M., Cappa, S., \& Fazio, F. (1999). Word and picture matching: a PET study of semantic category effects. Neuropsychologia, 37(3), 293-306.

Percer, J., \& Roediger III, H. (2001). Modality effects in false recall and false recognition. Learning, Memory, 27(2), 339-353. https://doi.org/10.3758/BF03193373

Pezdek, K., \& Lam, S. (2007). What research paradigms have cognitive psychologists used to study "false memory," and what are the implications of these choices? Consciousness and Cognition, 16(1), 2-17. https://doi.org/10.1016/j.concog.2005.06.006

Payne, D. G., Elie, C. J., Blackwell, J. M., \& Neuschatz, J. S. (1996). Memory illusions: Recalling, recognizing, and recollecting events that never occurred. Journal of Memory and Language, 35(2), 261-285. https://psycnet.apa.org/doi/10.1006/jmla.1996.0015

Reyna, V., \& Kiernan, B. (1994). Development of gist versus verbatim memory in sentence recognition: Effects of lexical familiarity, semantic content, encoding instructions, and retention interval. Developmental Psychology, 30(2), 178-191. https://psycnet.apa.org/doi/10.1037/00121649.30.2.178

Reyna, V. F., \& Brainerd, C. J. (1995). Fuzzy-trace theory: An interim synthesis. Learning and individual Differences, 7(1), 1-75. https://psycnet.apa.org/doi/10.1016/1041-6080(95)90031-4

Roediger, H., \& McDermott, K. (1995). Creating false memories: Remembering words not presented in lists. Journal of Experimental Psychology: Learning, Memory, and Cognition, 21(4), 803-814.

Roediger III, H., Balota, D., \& Watson, J. (2001). Spreading activation and arousal of false memories. In H.L. Roediger, III, J. S. Nairne, I. Neath, \& A. M. Surprenant (Eds.) The nature of remembering: Essays in honor of Robert G. Crowder, (p.95-115). American Psychological Association Press.

Sachs, J. (1967). Recognition memory for syntactic and semantic aspects of connected discourse. Attention, Perception, \& Psychophysics, 2(9), 437-442. https://doi.org/10.3758/BF03208784

Schacter, D., Alpert, N., Savage, C., Rauch, S., \& Albert, M. (1996). Conscious recollection and the 
human hippocampal formation: evidence from positron emission tomography. Proceedings of the National Academy of Sciences, 93(1), 321-325.

Schacter, D., Israel, L., \& Racine, C. (1999). Suppressing false recognition in younger and older adults: The distinctiveness heuristic. Journal of Memory and Language, 40(1), 1-24. https://doi.org/10.1006/jmla.1998.2611

Schacter, D., Cendan, D., Dodson, C., \& Clifford, E. (2001). Retrieval conditions and false recognition: Testing the distinctiveness heuristic. Psychonomic Bulletin \& Review, 8(4), 827-833.

Seamon, J. G., Luo, C. R., Schlegel, S. E., Greene, S. E., \& Goldenberg, A. B. (2000). False memory for categorized pictures and words: The category associates procedure for studying memory errors in children and adults. Journal of Memory and Language, 42(1), 120-146. https://psycnet.apa.org/doi/10.1006/jmla.1999.2676

Smith, R. E., \& Hunt, R. R. (1998). Presentation modality affects false memory. Psychonomic Bulletin \& Review, 5(4), 710-715. https://doi.org/10.3758/BF03208850

Sommers, M. S., \& Lewis, B. P. (1999). Who really lives next door: Creating false memories with phonological neighbors. Journal of Memory and Language, 40(1), 83-108. https://psycnet.apa.org/doi/10.1006/jmla.1998.2614

Snodgrass, J. G., \& Corwin, J. (1988). Pragmatics of measuring recognition memory: applications to dementia and amnesia. Journal of Experimental Psychology: General, 117(1), 34. https://psycnet.apa.org/doi/10.1037/0096-3445.117.1.34

Stadler, M. A., Roediger, H. L., \& McDermott, K. B. (1999). Norms for word lists that create false memories. Memory \& Cognition, 27(3), 494-500.

Strack, F., \& Bless, H. (1994). Memory for non-occurrences: Metacognitive and pre-suppositional strategies. Journal of Memory and Language, 33(2), 203-217. https://doi.org/10.1006/jmla.1994.1010

Thapar, A., \& McDermott, K. (2001). False recall and false recognition induced by presentation of associated words: Effects of retention interval and level of processing. Memory \& Cognition, 29(3), 424-432.

Toglia, M., \& Battig, W. (1978). Handbook of semantic word norms. Erlbaum. 
Toglia, M., \& Neuschatz, J. (1996). False memories: Where does encoding opportunity fit into the equation. In Poster presented at the 37th Annual Meeting of the Psychonomic Society, Chicago.

Toglia, M., Neuschatz, J., \& Goodwin, K. (1999). Recall accuracy and illusory memories: when more is less. Memory, 7(2), 233-256. https://doi.org/10.1080/741944069

Underwood, B. (1965). False recognition produced by implicit verbal responses. Journal of experimental psychology, 70(1), 122-129. http://doi.org/10.1037/h0022014

Weldon, M. S., \& Roediger, H. L. (1987). Altering retrieval demands reverses the picture superiority effect. Memory \& Cognition, 15(4), 269-280. https://doi.org/10.3758/BF03197030 


\section{Appendixes}

Semantic associate stimuli

Recall List (DRM) [Only partial list reproduced here]

\begin{tabular}{|c|c|}
\hline Word List 01 & Word List 02 \\
\hline $\begin{array}{l}\text { 1) stream } \\
\text { 2) flow } \\
\text { 3) bridge } \\
\text { 4) lake } \\
\text { 5) boat } \\
\text { 6) tide } \\
\text { 7) swim } \\
\text { 8) run } \\
\text { 9) fish } \\
\text { 10) water } \\
\text { Critical Lure: river }\end{array}$ & $\begin{array}{l}\text { smooth } \\
\text { tough } \\
\text { rugged } \\
\text { bumpy } \\
\text { jagged } \\
\text { riders } \\
\text { uneven } \\
\text { road } \\
\text { sand }\end{array}$ \\
\hline
\end{tabular}

Recognition (DRM) [Only partial list reproduced here]

\begin{tabular}{|c|c|}
\hline Word List 01 & Word List 02 \\
\hline $\begin{array}{l}\text { • rage } \\
\text { - mad } \\
\text { - enrage } \\
\text { - fury } \\
\text { - happy } \\
\text { - wrath } \\
\text { - hate } \\
\text { - fight } \\
\text { - fear } \\
\text { calm }\end{array}$ & $\begin{array}{l}\text { navy } \\
\text { soldier } \\
\text { marines } \\
\text { draft } \\
\text { uniform } \\
\text { march } \\
\text { captain } \\
\text { war } \\
\text { pilot } \\
\text { combat } \\
\text { Critical Lure: army }\end{array}$ \\
\hline Critical Lure: anger & \\
\hline
\end{tabular}




\section{Category Associate Stimuli}

Recognition [Partical list reproduced]

\begin{tabular}{|l|}
\hline \multicolumn{1}{|c|}{ Category List $\mathbf{0 1}$} \\
\multicolumn{1}{|c|}{ (Cloths) } \\
11) Socks \\
12) pant \\
13) shoe \\
14) skirt \\
15) sweater \\
16) gloves \\
17) belt \\
18) scarf \\
19) vest \\
20) bermuda \\
Critical Lure : shirt \\
\hline
\end{tabular}
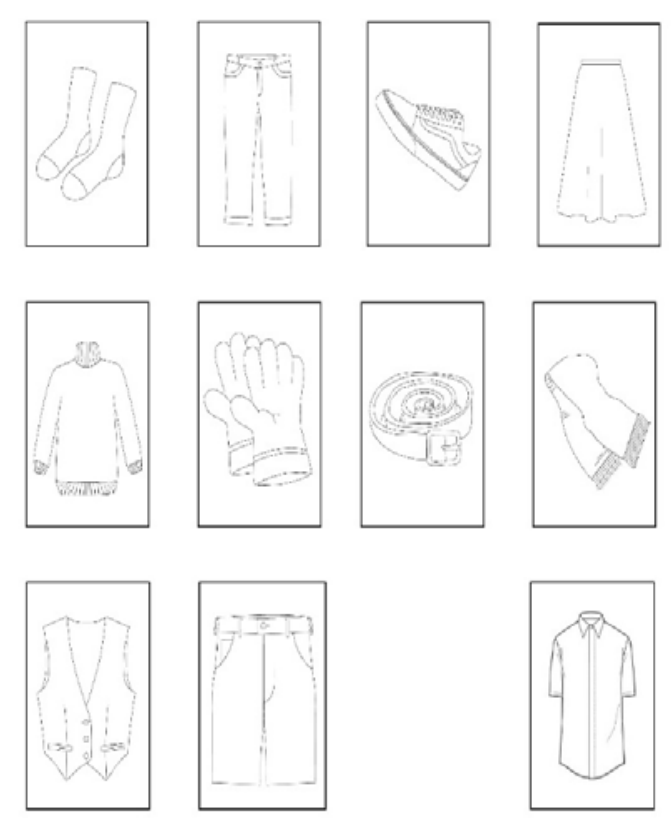

Recognition [Partical list reproduced]

\begin{tabular}{|l|}
\hline Category List 02 \\
(Furniture) \\
table \\
bed \\
sofa \\
desk \\
lamp \\
television \\
stool \\
bookcase \\
cupboard \\
\hline
\end{tabular}
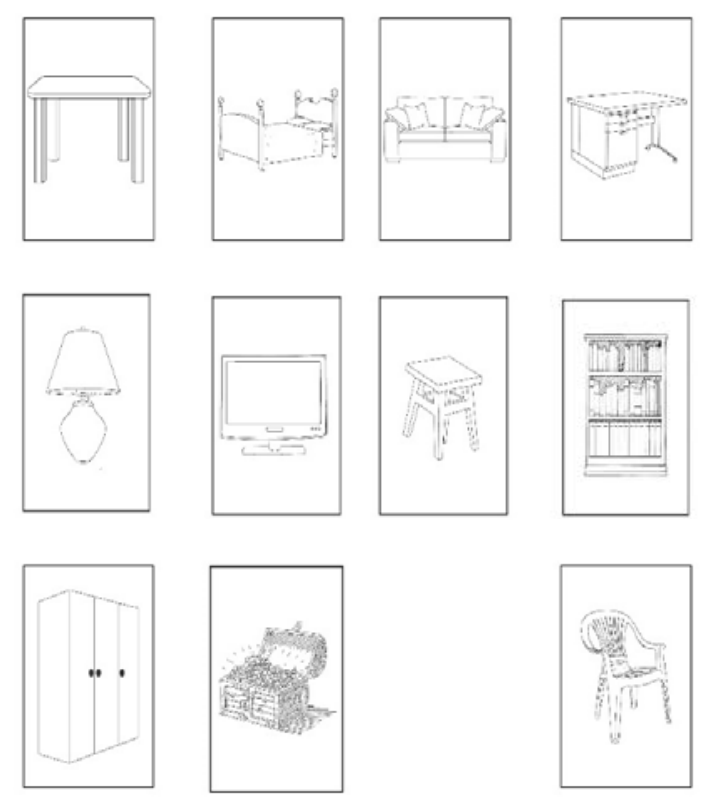
Recall [Partial list reproduced]

\begin{tabular}{|l|}
\hline \multicolumn{1}{|c|}{ Category List 01} \\
\multicolumn{1}{|c|}{ (Birds) } \\
eagle \\
crow \\
parrot \\
pigeon \\
chicken \\
duck \\
owl \\
ostrich \\
peacock \\
penguin \\
Critical Lure : \\
sparrow
\end{tabular}
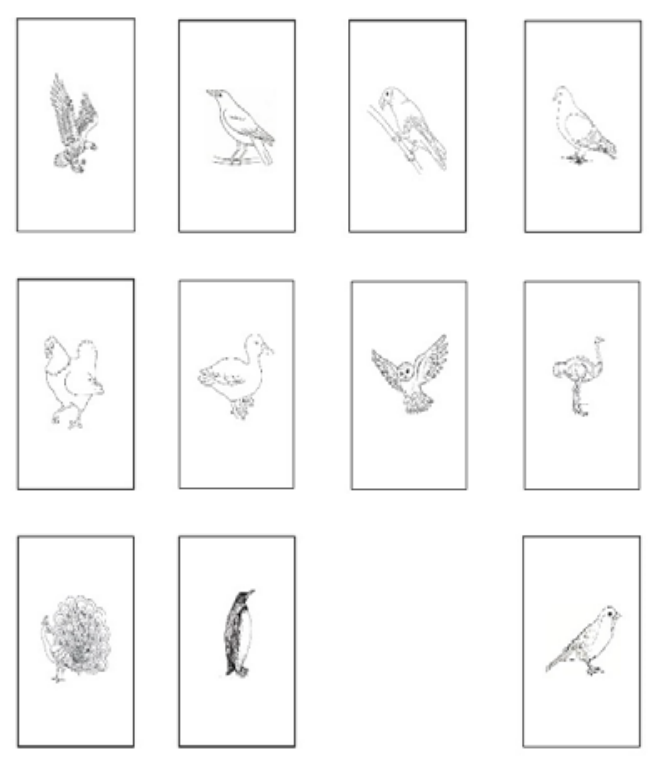

Recall [Partial list reproduced]

\begin{tabular}{|l|}
\hline \multicolumn{1}{|c|}{ Category List 02} \\
\multicolumn{1}{|c|}{$\quad$ (Insects) } \\
ant \\
bee \\
mosquito \\
spider \\
beetle \\
cockroach \\
grasshopper \\
butterfly \\
termite \\
caterpillar \\
Critical Lure : housefly \\
\hline
\end{tabular}
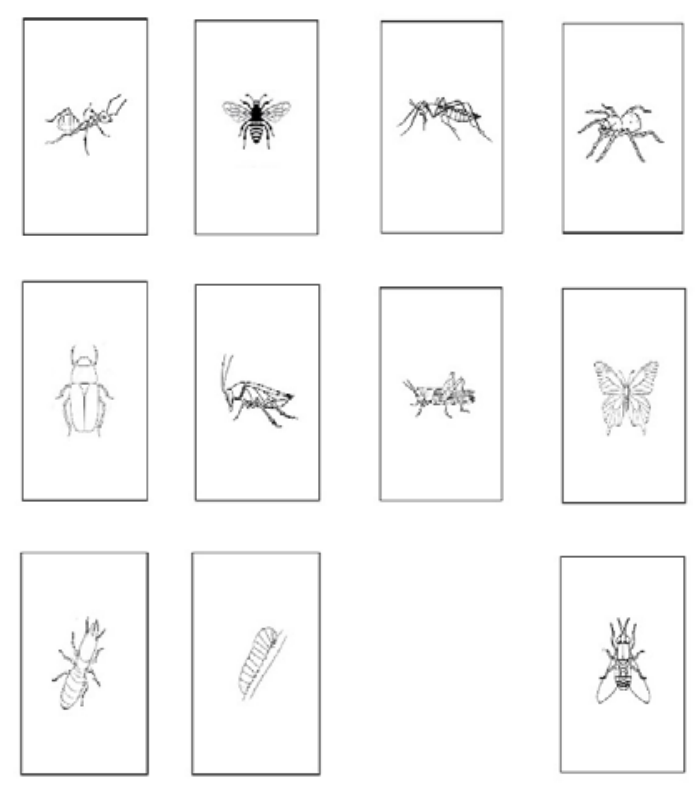


\section{About the authors}

Kedarmal Verma - The author is research scholar at the department of humanities and social sciences, Indian Institute of Technology Guwahati, India. The author's research interest is experimental psychology, cognition psychology and human memory.

Naveen Kashyap - The author is an associate professor of psychology at the department of humanities and social sciences, Indian Institute of Technology Guwahati, India. The author's research interest is experimental psychology, cognition psychology and human memory.

\section{Corresponding Author's Contact Address ${ }^{[T O P]}$}

Naveen Kashyap

Department of Humanities and Social Sciences, Indian Institute of Technology Guwahati,

Assam 781 039, India

naveen.kashyap@iitg.ac.in 